\title{
Endocervical Adenocarcinoma, Usual Type
}

National Cancer Institute

\section{Source}

National Cancer Institute. Endocervical Adenocarcinoma, Usual Type. NCI Thesaurus. Code C127907.

An adenocarcinoma that arises from the endocervix. It is the most common type of endocervical adenocarcinoma. The neoplastic epithelium shows a pseudostratified architecture and the malignant cells have enlarged, elong ated, and hyperchromatic nuclei. 